\title{
Mecamylamine Attenuates Cue-Induced Reinstatement of Nicotine-Seeking Behavior in Rats
}

\author{
Xiu Liu*, ${ }^{*, 2}$, Anthony R Caggiula', Susan K Yee ${ }^{2}$, Hiroko Nobuta ${ }^{2}$, Alan F Sved ${ }^{3}$, Robert N Pechnick ${ }^{2}$ \\ and Russell E Poland ${ }^{2}$ \\ 'Department of Psychology, University of Pittsburgh, Pittsburgh, PA, USA; ${ }^{2}$ Department of Psychiatry, Cedars-Sinai Medical Center, \\ Los Angeles, CA, USA; ${ }^{3}$ Department of Neuroscience, University of Pittsburgh, Pittsburgh, PA, USA
}

\begin{abstract}
Mecamylamine, a noncompetitive nicotinic cholinergic antagonist, inhibits nicotine self-administration in animals and may attenuate tobacco smoking in humans trying to quit. Our preliminary data suggested that this agent, at a dose of $2 \mathrm{mg} / \mathrm{kg}$ (subcutaneous (s.c.)), also attenuates cue-induced relapse to nicotine-seeking behavior in rats. This study determined whether mecamylamine-induced attenuation can be obtained at doses lower than the high $2 \mathrm{mg} / \mathrm{kg}$ dose used in the first study, and whether it is specific to nicotine-associated cues. Male Sprague-Dawley rats were trained to intravenously self-administer nicotine $(0.03 \mathrm{mg} / \mathrm{kg} / \mathrm{infusion})$ on a fixed-ratio 5 schedule. Each infusion was accompanied by a visual cue (I s onset of a lever light followed by offset of a house light for $20 \mathrm{~s}$ during which time no infusions could be obtained). After the nicotine-maintained responding was extinguished by withholding the delivery of nicotine (saline substitution) and its associated cue, reinstatement tests were conducted. Response-contingent re-presentation of the cue without further availability of nicotine significantly reinstated extinguished responding at the previously nicotine-reinforced lever. Pretreatment with mecamylamine $(0.5,1$, and $2 \mathrm{mg} / \mathrm{kg}, \mathrm{s.c}$.) dose-dependently attenuated the cue-induced reinstatement of lever responding. Mecamylamine did not change food-taking and -seeking responses, whereas the highest dose $(2 \mathrm{mg} / \mathrm{kg})$ decreased nicotine selfadministration behavior. The results confirm previous findings that stimuli conditioned to nicotine self-administration effectively elicit reinstatement of nicotine-seeking behavior after extinction and demonstrate that mecamylamine, besides suppressing self-administration of nicotine, effectively attenuates cue-induced nicotine-seeking behavior. These findings suggest that the response-reinstatement procedures used in this study may be useful for studying neurobiological mechanisms of nicotine-seeking behavior and that mecamylamine-like drugs may be potential candidates for pharmacological treatment and prevention of relapse to tobacco smoking in abstinent smokers.

Neuropsychopharmacology (2007) 32, 710-718. doi:I0.1038/sj.npp. I 301 I29; published online 21 June 2006
\end{abstract}

Keywords: nicotine; mecamylamine; self-administration; conditioned stimulus; nicotine-seeking behavior; reinstatement

\section{INTRODUCTION}

Tobacco smoking is a chronic relapsing disorder, characterized by a recurrent resumption of smoking after abstinence; only approximately $3 \%$ of smokers trying to quit successfully remain abstinent each year (Shiffman et al, 1998). Nicotine is the principal psychoactive component of cigarette smoke and non-nicotine stimuli that become associated with nicotine delivery are thought to play an important role in the maintenance of smoking and in its relapse after attempted quitting (Caggiula et al, 2001;

* Correspondence: Dr X Liu, Department of Psychology, University of Pittsburgh, 3131 Sennott Square, 120 S Bouquet Street, Pittsburgh, PA 15260, USA, Tel: + I 4126247345 , Fax: + I 4126248558 ,

E-mail: xiuliu@pitt.edu

Received II December 2005; revised 26 April 2006; accepted 9 May 2006

Online publication: 22 May 2006 at http://www.acnp.org/citations/ Npp0522060507/8/default.pdf
Childress et al, 1993; Niaura et al, 1989; O’Brien et al, 1998). Human studies have demonstrated that smoking cues increase the rate, intensity, and time of smoking (Mucha et al, 1998; Surawy et al, 1985) and significantly enhance desire to smoke (Drobes and Tiffany, 1997; Droungas et al, 1995; Lazev et al, 1999; Payne et al, 1991; Tiffany and Hakenewerth, 1991). Smoking denicotinized cigarettes (ie cue alone) produces comparable levels of smoke intake, satisfaction, and reduction of craving and withdrawal compared to smoking nicotine-containing cigarettes (ie cue plus nicotine) (Butschky et al, 1995; Dallery et al, 2003; Gross et al, 1997; Rose et al, 2000; Shahan et al, 1999).

In animal self-administration experiments, the infusion of nicotine is typically paired with discrete stimulus events, such as the onset or offset of cue and chamber lights (Caggiula et al, 2001; Cohen et al, 2005; Corrigall and Coen, 1989; Goldberg et al, 1981; LeSage et al, 2004; Liu et al, 2003, 2006; Paterson et al, 2005). For example, Goldberg et al (1981) found a $50 \%$ decrease in nicotine self-administration 
in squirrel monkeys when a brief light stimulus that had been associated with the drug was omitted. Rats spontaneously recovered previously extinguished behavior after re-exposure to the nicotine self-administration context after being maintained in their home cages for 21 days (Shaham et al, 1997). In recent studies using a response-reinstatement model of nicotine relapse, it has been documented that reintroduction of the discrete stimulus previously associated with nicotine self-administration effectively reinstates extinguished nicotine-seeking responses in rats (Caggiula et al, 2001; Cohen et al, 2005; LeSage et al, 2004; Liu et al, 2006; Paterson et al, 2005).

Neuronal nicotinic acetylcholine receptors (nAChRs) mediate the physiological and behavioral effects of nicotine. For example, we have shown that rats readily selfadminister a $\beta 2$-selective nicotinic receptor agonist (Liu et al, 2003). Conversely, nicotinic receptor antagonists have been found to block nicotine's effects on striatal dopamine release and turnover (Haikala and Ahtee, 1988; Nisell et al, 1994), nicotine-induced dopaminergic signaling and neuronal excitation (Hamada et al, 2004; Yin and French, 2000), the locomotor effects of nicotine (Clarke and Kumar, 1983; Curzon et al, 1996; Kuo et al, 1999), and nicotine-induced hypothermia (Haikala and Ahtee, 1988; Zarrindast et al, 2001). Similarly, nicotinic antagonists precipitate nicotine withdrawal (Adams and Cicero, 1998; Hildebrand et al, 1999; Watkins et al, 2000b) and decrease rates of nicotine self-administration (Corrigall and Coen, 1989; Donny et al, 1999; Shoaib et al, 1997; Watkins et al, 1999). In human studies, nicotinic receptor antagonists effectively reduce ratings of reward of smoking (Rose and Behm, 2004; Rose et al, 1994, 1998) and help sustain smoking cessation in conjunction with nicotine replacement therapy (Rose et al, 1994, 1998). In addition, there is evidence that nicotine, acting through nAChRs, can influence attention, associative learning, and memory (Blokland, 1995; Olausson et al, 2003; Rezvani and Levin, 2001). Most importantly, our recent data (Liu et al, 2006) show that mecamylamine, a nonselective nAChR antagonist (Takayama et al, 1989), at a dose of $2 \mathrm{mg} / \mathrm{kg}$ substantially attenuates cue-induced reinstatement of nicotine-seeking behavior. Taken together, these findings suggest that activation of nicotinic receptors may also be important in mediating the incentive motivational effects of nicotineassociated environmental stimuli.

To further characterize involvement of nicotinic activation in nicotine relapse associated with cue exposure, we employed a response-reinstatement model of relapse to examine the dose-effect relationship and the specificity of mecamylamine to inhibit nicotine-seeking elicited by reexposure to a visual cue that had been repeatedly paired with nicotine infusions during extended nicotine selfadministration training. An increasing number of studies using this response-reinstatement model of relapse for stimulants, opiates, and alcohol have provided important information for understanding the behavioral and neurobiological bases of drug use and relapse (Epstein and Preston, 2003; Kalivas and McFarland, 2003; Shaham et al, 2003 for reviews). Recently, we (Caggiula et al, 2001; Liu et al, 2006) as well as others (Cohen et al, 2005; LeSage et al, 2004; Paterson et al, 2005) have validated the responsereinstatement procedures for demonstrating the signifi- cance of nicotine-associated cues in eliciting recovery of extinguished nicotine-seeking responses.

\section{MATERIALS AND METHODS}

\section{Subjects}

Seventy-two male Sprague-Dawley rats (Charles River) weighing 225-250 g upon arrival were individually housed in a humidity- and temperature-controlled $\left(21-22^{\circ} \mathrm{C}\right)$ colony room on a reversed $12: 12 \mathrm{~h}$ light/dark cycle (lights off 0700 hours) with unlimited access to water. After 1 week of habituation with free access to food, animals were placed on a food-restricted diet for all experiments as described below. All training and experimental sessions were conducted during the dark phase at the same time each day (0900-1500 hours). All experimental procedures were carried out in accordance with the National Institutes of Health Guide for the Care and Use of Laboratory Animals.

\section{Apparatus}

All experimental sessions were conducted in operant conditioning chambers located inside sound-attenuating, ventilated cubicles (Med Associates, St Albans, VT). The chambers were equipped with two response levers on one side panel, with a $28-\mathrm{V}$ white light above each lever and a white house light on the top of the chambers. Between the two levers was a food receptacle. Intravenous (i.v.) nicotine injections were delivered by a drug delivery system with a syringe pump (Med Associates, model PHM100-10 rpm). Experimental events and data collection were controlled by an interfaced computer and software (Med Associates, MED-PC 2.0).

\section{Food Training}

After habituation to the colony room, animals were handled twice/day for 3 days and placed on a food-restricted diet of $20 \mathrm{~g} /$ day. Food training sessions began under a fixed-ratio (FR) 1 schedule where each lever press on one of the two levers resulted in the delivery of a food pellet $(45 \mathrm{mg})$. The assignment of the active lever was counterbalanced between the right and the left levers across animals. Daily sessions lasted 1-h with a maximum delivery of 100 food pellets. After the rats successfully earned 100 food pellets, the reinforcement schedule was increased to FR5 with a maximum of 50 food pellets delivered in each 1 -h session. Responses at the inactive lever had no consequence. During the food training sessions, there was no presentation of the house light and lever light, which prevented an association of the visual cue (see below) with food reward at this stage.

\section{Surgery}

After food training, rats designated to nicotine selfadministration/reinstatement experiments were anesthetized with halothane and implanted with jugular catheters as described previously (Caggiula et al, 2001). Animals were allowed at least 7 days to recover from surgery and catheters were flushed twice/day with $0.1 \mathrm{ml}$ of sterile saline containing heparin $(30 \mathrm{U} / \mathrm{ml})$, Timentin $(66.67 \mathrm{mg} / \mathrm{ml})$, and 
streptokinase $(8333 \mathrm{U} / \mathrm{ml})$ to maintain catheter patency and prevent infection. Thereafter, the catheters were flushed with heparinized saline before and after sessions throughout the experiments.

\section{Nicotine Self-Administration/Conditioning}

Rats were trained in daily 1 -h sessions to self-administer nicotine delivered together with a visual cue. The sessions were initiated with extension of the two levers and illumination of the house light. Once the rats reached the FR requirement at the active lever, an i.v. infusion of nicotine $(0.03 \mathrm{mg} / \mathrm{kg}$, free base) was delivered in a volume of $0.1 \mathrm{ml}$ in approximately $1 \mathrm{~s}$. Each nicotine infusion was paired with presentation of a visual cue that consisted of $1 \mathrm{~s}$ illumination of the light above the active lever and extinction of the house light for $20 \mathrm{~s}$, indicating a time out period during which time responses were recorded, but not reinforced. An FR1 schedule was used for days 1-5, an FR2 for days 6-8, and an FR5 for the remaining 22 days. Rats were considered to have successfully established stable nicotine self-administration if they met a criterion of $\geqslant 6$ infusions/session with $\leqslant 20 \%$ variation for at least three consecutive sessions. Responses at the inactive lever were recorded, but had no programmed consequence.

\section{Food Self-Administration/Conditioning}

To make food self-administration/conditioning comparable to that of nicotine, the daily $1-\mathrm{h}$ sessions were conducted under conditions identical to that described above, except that food pellets rather than nicotine injections were delivered. Specifically, an FR1 was used for days 1-5, an FR2 for days 6-8, and an FR5 for the following 22 days. Once rats completed the FR requirement at the active lever, a food pellet was delivered with a presentation of the visual cue ( $1 \mathrm{~s}$ illumination of the lever light and $20 \mathrm{~s}$ turn-off of the house light). The maximum number of food pellets available for animals to earn was 50 across the 1-h sessions.

\section{Extinction}

After completion of 30 daily sessions of self-administration/ conditioning training, the nicotine- or food-reinforced responses were extinguished by withholding nicotine or food and its associated visual cue. Specifically, the house light remained on during the whole sessions and there was no presentation of the $1 \mathrm{~s}$ light above the active lever. Responses at the active lever resulted in only the delivery of saline rather than nicotine for nicotine-reinforced rats or nothing for food-reinforced rats. Responses at the inactive lever were recorded, but had no consequence. The criterion for extinction was that for 3 consecutive days responses/ session decrease to $<20 \%$ of that obtained during the selfadministration phase.

\section{Reinstatement Tests and Pharmacological Treatments}

One day after the final extinction session, nicotine-trained rats were divided into four groups $(n=8)$ in a counterbalanced manner so that each group had similar rates of operant responding during self-administration/condition- ing and extinction phases. Reinstatement tests were conducted under conditions identical to that of selfadministration/conditioning, except that a single presentation of the cue was delivered response-independently immediately after the start of the session and then responses at the active lever (on an FR5 schedule) resulted in contingent presentation of the cue without nicotine availability (saline substitution). Responses at the inactive lever were recorded without consequence. The testing sessions lasted $1 \mathrm{~h}$. For pharmacological tests, rats were subjected to subcutaneous (s.c.) administration of mecamylamine at one of four doses, 0 (saline), $0.5,1.0$, or $2.0 \mathrm{mg} / \mathrm{kg}, 30 \mathrm{~min}$ before the reinstatement test sessions.

Similar to nicotine rats described above, the rats for reinstatement test of cue-induced food-seeking with mecamylamine pretreatment were also divided into four groups $(n=8)$. Both the testing sessions and mecamylamine pretreatments were identical to that described above, with the exception that there was no food pellet available throughout the session and responses at the active ever resulted in only presentation of the cue on an FR5 schedule.

\section{Self-Administration Tests and Pharmacological Treatments}

After the reinstatement tests, animals were retrained in 10 daily 1 -h sessions to self-administer nicotine or food as described above. Stable levels of self-administration of either nicotine or food pellets were re-established within 5-7 sessions. Rats from each drug dose group in the reinstatement tests were equally distributed into the four drug dose groups for the self-administration tests. Thus, the eight rats in each dose group in the following selfadministration tests contained two rats from each dose group in the previous reinstatement tests. Designation of rats into different groups was also counterbalanced based on their operant responses so that each group had a similar number of lever responses before test. Thirty minutes after administration of mecamylamine $(0,0.5,1.0$, and $2.0 \mathrm{mg} / \mathrm{kg}$ s.c.), the self-administration tests for nicotine or food were conducted under conditions identical to the self-administration (nicotine or food) sessions as described above.

\section{Statistical Analyses}

Eight rats were excluded from data analysis due to failure of catheter patency (five) and stable nicotine self-administration at criterion (three). Behavioral data, presented as the mean $( \pm$ SEM) number of lever responses, were analyzed by using one-factor ANOVA with subsequent Newman-Keuls post hoc tests to verify differences among individual means. Student's $t$-test was used to directly compare between groups wherever appropriate (see Results).

\section{RESULTS}

\section{Nicotine or Food Self-Administration and Extinction}

Animals developed stable levels of nicotine self-administration after 30 daily 1-h self-administration training sessions. Averaged across the last three sessions, response rates were $104.1 \pm 6.0$ at the active lever and $16.9 \pm 1.7$ at the inactive 
lever, resulting in $19.1 \pm 1.2$ nicotine infusions per 1 -h session. In the first extinction session, rats emitted $87.3 \pm 21.9$ responses at the active lever and $18.2 \pm 8.1$ at the inactive lever. During the following extinction sessions, lever responses gradually decreased. All rats reached the extinction criterion in $14 \pm 2$ sessions. There was no difference across groups assigned for subsequent reinstatement and pharmacological tests. Table 1 shows the detailed number of responses.

In food-reinforced rats, average responses during the last three sessions were $395.8 \pm 29.4$ at the active lever and $25.4 \pm 8.7$ at the inactive lever. After 14 daily extinction sessions, the mean \pm SEM number of responses was $8.0 \pm 0.7$ at the active lever and $5.1 \pm 0.6$ at the inactive lever averaged across the last three sessions. There was no difference across groups assigned for subsequent reinstatement and pharmacological tests. Table 2 shows the detailed number of responses.

\section{Effect of Mecamylamine on Cue-Induced Reinstatement of Nicotine-Seeking}

In the vehicle-treated rats, response-contingent presentation of the nicotine-associated visual cue significantly reinstated responding at the active lever with mean ( \pm SEM) number of $63 \pm 11$ responses $v s 19 \pm 4$ at extinction $(\mathrm{t}(7)=4.72, p<0.01)$. Pretreatment with mecamylamine dose-dependently attenuated the cue-induced responsereinstatement. A one-factor ANOVA revealed a significant group (dose) effect $(F(3,28)=4.08, p<0.05)$. Subsequent Newman-Keuls post hoc tests verified significant differences in reinstatement responses between vehicle vs $1 \quad(p<0.05)$ and $2 \mathrm{mg} / \mathrm{kg}(p<0.01)$ groups (Figure 1, top). However, responses at the inactive lever as shown in the lower panel of Figure 1 were not affected by pretreatment $(\mathrm{F}(3,28)=$ $0.07, p=0.98)$.

\section{Effect of Mecamylamine on Cue-Induced Reinstatement of Food-Seeking}

In the reinstatement tests for cue-induced food-seeking behavior, response-contingent presentation of the visual cue effectively produced an increase in responding at the active lever with a mean $( \pm$ SEM) number of $44 \pm 6$ responses $v s 9 \pm 3$ at extinction in vehicle-pretreated rats $(\mathrm{t}(7)=4.72, p<0.01$ ) (Figure 2, top). A one-factor ANOVA analysis yielded no significant group effect $(\mathrm{F}(3,28)=0.03$, $p=0.99$ ), indicating lack of an effect of mecamylamine pretreatment.

\section{Effect of Mecamylamine on Nicotine Self-Administration}

A one-way ANOVA on the number of active lever responses yielded a marginal group/dose effect $(\mathrm{F}(3,28=2.61$, $p=0.07)$. An unpaired $t$-test analysis revealed a significant difference between mecamylamine at the highest dose $2.0 \mathrm{mg} / \mathrm{kg} v s$ vehicle $(\mathrm{t}(14)=2.18, p<0.05)$, indicating a significant decrease in responding at the active lever for delivery of nicotine (Figure 3). However, there was no change in the inactive lever responses.

\section{Effect of Mecamylamine on Food Self-Administration}

In the food self-administration tests, pretreatment with mecamylamine produced no change in operant responses as shown in Figure 4.

\section{DISCUSSION}

Response-contingent presentation of a nicotine-associated visual cue induced resumption of nicotine-seeking behavior after extinction, as reflected by reinstatement of leverpressing at the previously nicotine-reinforced, active lever in the vehicle-treated rats. As responding at the inactive lever remained unchanged, this effect is not likely to be the result of nonspecific behavioral arousal. This finding is consistent with several recent reports in rats (Caggiula et al, 2001; Cohen et al, 2005; LeSage et al, 2004; Liu et al, 2006; Paterson et al, 2005) and lends support to clinical observations that smoking-related cues enhance desire to smoke (Drobes and Tiffany, 1997; Droungas et al, 1995; Lazev et al, 1999; McDermut and Haaga, 1998).

An important goal of this study was to examine whether reinstatement of responding produced by re-exposure to the nicotine-associated cue is sensitive to pharmacological

Table I Active Lever Responses and Body Weights in Nicotine-Trained Rats

\begin{tabular}{|c|c|c|c|c|}
\hline Group/dose ( $n=8$ each) & 0 & 0.5 & 1.0 & 2.0 \\
\hline Self-administration (last session) & $98 \pm 12$ & $108 \pm 16$ & $106 \pm 8$ & $103 \pm 7$ \\
\hline Extinction (first session) & $84 \pm 9$ & $86 \pm 7$ & $89 \pm 12$ & $90 \pm 13$ \\
\hline
\end{tabular}

Table 2 Active Lever Responses and Body Weights in Food-Trained Rats

\begin{tabular}{|c|c|c|c|c|}
\hline Group/dose ( $n=8$ each) & $\mathbf{0}$ & 0.5 & 1.0 & 2.0 \\
\hline Self-administration (last session) & $389 \pm 12$ & $392 \pm 15$ & $400 \pm 25$ & $399 \pm 18$ \\
\hline Extinction (first session) & $65 \pm 14$ & $69 \pm 8$ & $76 \pm 20$ & $68 \pm 12$ \\
\hline Body weight before reinstatement & $360 \pm 25$ & $368 \pm 22$ & $351 \pm 16$ & $348 \pm 23$ \\
\hline
\end{tabular}



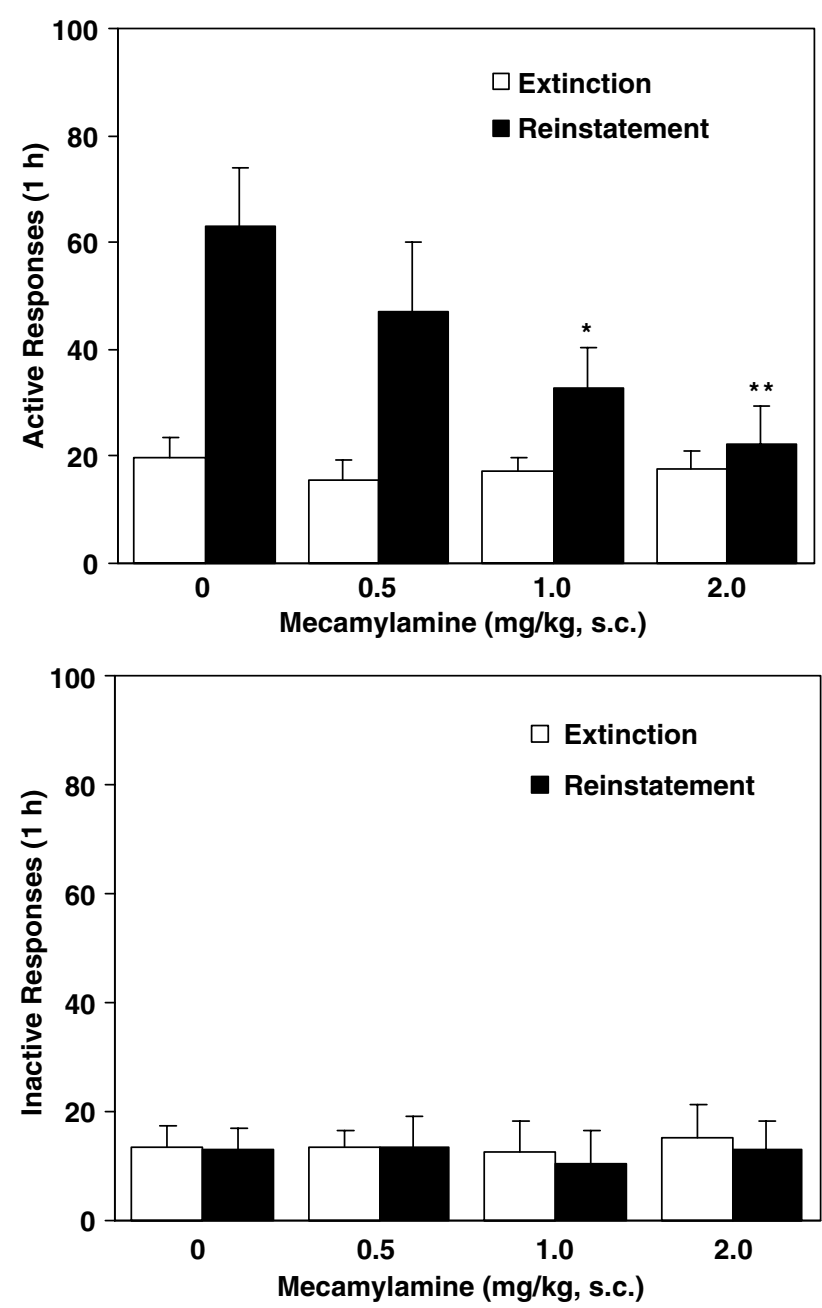

Figure I Effect of mecamylamine on responses made at the active (top) and the inactive (below) levers during the reinstatement tests for nicotineseeking behavior. After 30 daily I-h nicotine self-administration/conditioning training sessions, nicotine-maintained responses were extinguished by saline substitution for nicotine and withholding presentation of the visual cue. Thirty minutes before behavioral tests, rats received s.c. administration of mecamylamine. In the reinstatement test sessions, responses at the active lever resulted in contingent presentation of the cue (I s lever light on followed by 20 s house light off) without delivery of nicotine infusion (saline substitution), whereas responding at the inactive lever had no consequence. For comparison, extinction responses (averaged across the last three sessions) without mecamylamine pretreatment were provided. The number of responses was presented as mean \pm SEM in each group $(n=8)$ ${ }^{*} p<0.05 ; *^{*} p<0.0$ I different from vehicle.

antagonism of nicotinic neurotransmission. Mecamylamine was selected as the nAChR antagonist because it has been reported to completely inhibit the discriminative stimulus effects of nicotine (Mansbach et al, 2000; Varvel et al, 1999) and decrease nicotine self-administration in animals (Corrigall and Coen, 1989; Donny et al, 1999; Shoaib et al, 1997; Watkins et al, 1999). In humans, mecamylamine reduces self-reported nicotine-liking and estimates of dose strength following nicotine infusion (Rose et al, 1995), the desire to smoke (Rose et al, 1989), and satisfaction derived from smoking (Lundahl et al, 2000; Nemeth-Coslett et al, 1986; Rose et al, 1994). Pretreatment with this agent (0.5$2.0 \mathrm{mg} / \mathrm{kg}$ ) before behavioral tests dose-dependently atte-
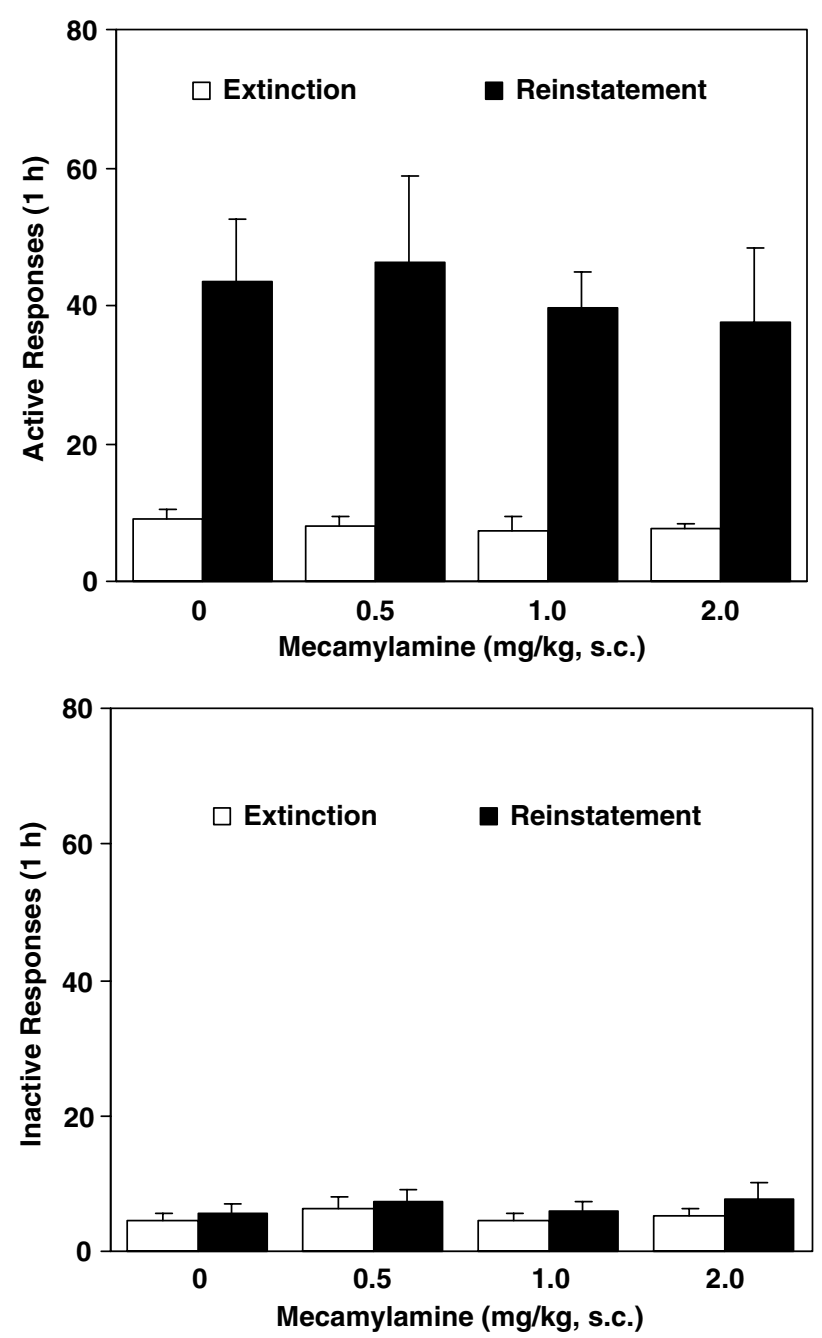

Figure 2 Effect of mecamylamine on responses at the active (top) and the inactive (below) levers made during the reinstatement tests for foodseeking behavior. After 30 daily I-h food self-administration/conditioning training sessions, lever responses were extinguished by withholding delivery of food pellets and presentation of the visual cue. Thirty minutes after s.c. administration of mecamylamine, the reinstatement test sessions were conducted where responses at the active lever resulted in presentation of the cue without delivery of food pellets, whereas responding at the inactive lever had no consequence. For comparison, extinction responses (averaged across the last three sessions) without mecamylamine pretreatment were provided. The number of responses was presented as mean \pm SEM in each group $(n=8)$.

nuated response-reinstatement induced by presentation of the nicotine-associated cue. It is likely that these results were due to antagonistic action at nicotinic receptors located in the brain (Eissenberg et al, 1996; Loiacono et al, 1993; Varanda et al, 1985) and not the result of nonspecific impairment of general locomotor activity or ganglionic blockade-induced hypotension. Mecamylamine attenuated responses only at the active but not the inactive lever and it did not affect responding maintained by food reinforcement and response-reinstatement produced by food-associated cue. In addition, observations from other laboratories have shown that mecamylamine in the dose range used here did not affect operant responding for 


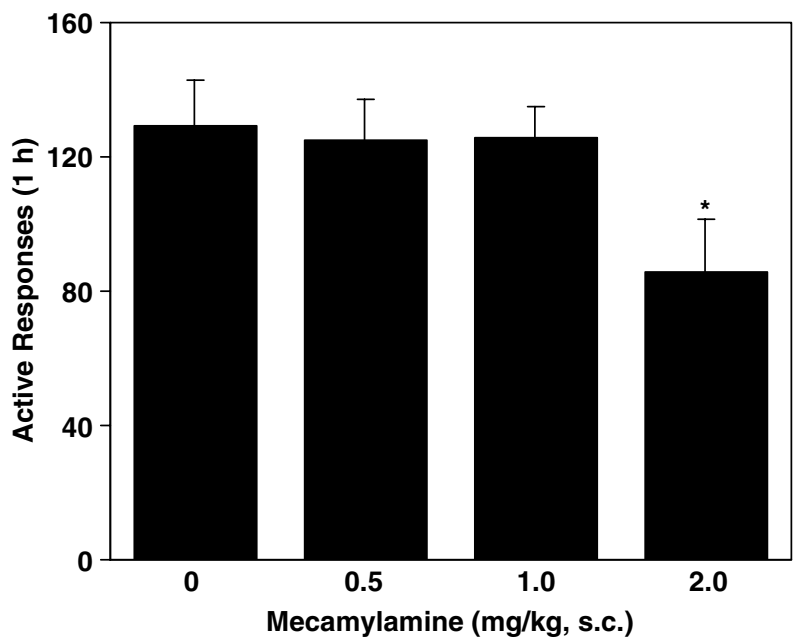

Figure 3 Effect of mecamylamine on lever responses maintained by i.v. nicotine infusions. In the self-administration test sessions conducted $30 \mathrm{~min}$ after s.c. administration of mecamylamine, responses at the active lever resulted in delivery of nicotine infusion and its associated presentation of the visual cue, whereas responding at the inactive lever had no consequence. The number of responses was presented as the mean \pm SEM in each group $(n=8) .{ }^{*} p<0.05$ different from vehicle.

natural rewards such as food (Mansbach et al, 2000) or water (Glick et al, 2002). Moreover, our recent work (Liu et al, 2006, paper presentation at SRNT annual meeting) shows that mecamylamine produced no effect on leverpressing maintained by visual stimulus ( $60 \mathrm{~s}$ turn-off of house light in rat dark phase) that had not been conditioned to nicotine. Taken together, these data rule out the possibility of nonspecific impairment of general locomotor activity by mecamylamine. The present finding not only confirms our previous observation that mecamylamine at the highest dose of $2.0 \mathrm{mg} / \mathrm{kg}$ produced inhibition on cueelicited nicotine-seeking responses (Liu et al, 2006) but also provides information on dose dependency of reinstatement attenuation by this agent.

Of particular significance is that this study further examined the specificity of mecamylamine to attenuate response-reinstatement by nicotine-associated visual cue. Nicotinic neurotransmission has been implicated in mediating processes of cognitive attention, associative learning, and memory (Blokland, 1995; Olausson et al, 2003; Rezvani and Levin, 2001). Thus, it is possible that the attenuation of reinstatement by mecamylamine might be due to a more general inhibitory effect on conditioned goal-directed responses rather than a specific action on cue-induced nicotine-seeking. In separate groups of animals of the present study, the same visual stimulus was exclusively paired with delivery of a natural reward, food pellets. After extinction, the food-associated cue significantly increased responding at the previously food-reinforced lever, indicating that the cue acquired conditioned incentive value via pairing with food pellet deliveries and thereby reinstated food-seeking behavior. However, mecamylamine pretreatment failed to interfere with the cue-induced food-seeking responses, supporting a more specific effect of mecamylamine on nicotine-seeking. The inhibitory effect on conditioned reinstatement of nicotine-seeking after abstinence

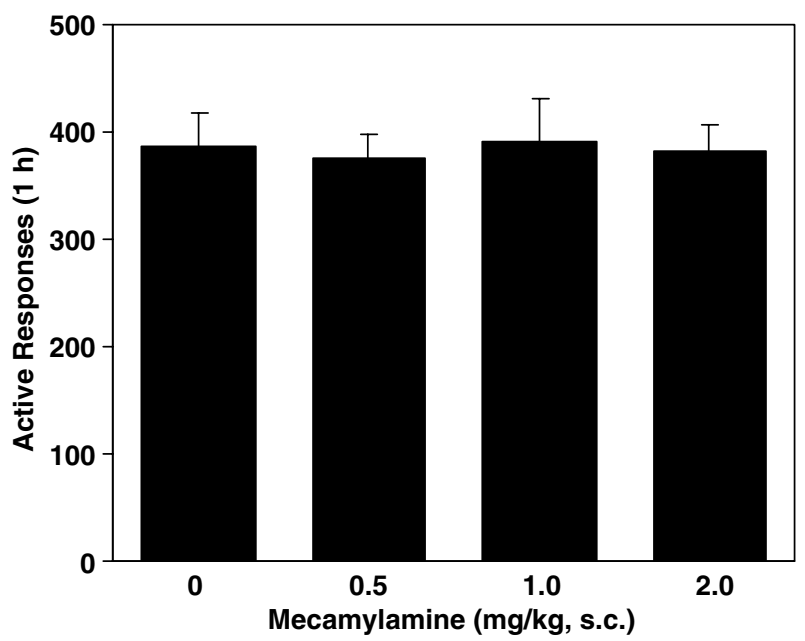

Figure 4 Effect of mecamylamine on food-reinforced lever responses. In the test sessions conducted 30 min after s.c. administration of mecamylamine, responses at the active lever resulted in delivery of food pellets and presentation of the visual cue, whereas responding at the inactive lever had no consequence. The number of responses was presented as the mean \pm SEM in each group $(n=8)$.

and extinction suggests that mecamylamine may be useful clinically in preventing relapse triggered by smoking-related environmental stimuli. Previously, Rose et al (1994) documented that co-administration of mecamylamine with nicotine transdermal patch improved the rate of abstinence in smokers by possibly reducing craving (with nicotine patches attenuating withdrawal symptoms). Moreover, it is interesting to note that in humans mecamylamine has been found to effectively reduce drug cue-induced cocaine craving (Reid et al, 1999). Together with the fact that there is an interaction between cigarette smoking and abuse of psychoactive drugs such as cocaine (Bechtholt and Mark, 2002; Horger et al, 1992; Kouri et al, 2001; Pich et al, 1997; Reid et al, 1998), it is suggested that mecamylamine may become a potentially effective anti-craving agent for relapse prevention for not only tobacco smoking but also cocaine and likely other psychostimulant use.

It is interesting to note the differences in the efficacy of mecamylamine in attenuating cue-induced reinstatement and nicotine self-administration. Specifically, mecamylamine attenuation of cue-induced reinstatement exhibited an orderly dose-effect function and was statistically significant at 1 and $2 \mathrm{mg} / \mathrm{kg}$, whereas only the highest dose of $2 \mathrm{mg} / \mathrm{kg}$ produced a slight but statistically significant decrease in lever responses for i.v. nicotine self-administration. The effective dose for reducing nicotine selfadministration is consistent with previous reports. For instance, Watkins et al (1999) found that mecamylamine at $2 \mathrm{mg} / \mathrm{kg}$ or higher but not $1 \mathrm{mg} / \mathrm{kg}$ reduced nicotine selfadministration under conditions similar to the present study. Taken together, these data indicate that conditioned response to nicotine-associated cues is more sensitive to acute pharmacological blockade of nicotinic neurotransmission than behavior maintained by nicotine selfadministration. There are two possible explanations for this phenomenon. First, the different sensitivity to 
mecamylamine may stem from distinct neuronal circuitries that are involved in mediating the primary reinforcing actions of nicotine and the conditioned incentive motivation by nicotine-associated cues. Recent studies have shown that neuroanatomical, neurochemical, and neuropharmacological substrates underlying cue-induced reinstatement of drug-seeking behavior are, to some extent, different from those mediating the direct reinforcing actions of drugs of abuse (Grimm and See, 2000; Kalivas and McFarland, 2003; Kantak et al, 2002; Liu and Weiss, 2004). For instance, Liu and Weiss (2004) found that nitric oxide synthesis inhibition attenuated conditioned reinstatement of ethanol-seeking, but not the primary reinforcing effects of ethanol. Naltrexone, an opioid antagonist, attenuated reinstatement of methamphetamine-seeking behavior induced by drug-associated cues but not drug-priming (Anggadiredja et al, 2004). The issue whether distinct neurobiological mechanisms are involved in mediating conditioned reinstatement of nicotine-seeking behavior and the primary reinforcing actions of nicotine warrants future study. Second, ample evidence has shown desensitization, an inactive conformation of nicotinic receptors after nicotine exposure (Lukas et al, 1996; Mansvelder et al, 2002). For example, it was shown that six daily nicotine injections resulted in the development of tolerance to its antinociception actions (McCallum et al, 2000) and that nicotinic receptor function could be lost for $>24 \mathrm{~h}$ following chronic nicotine exposure (Girod and Role, 2001). In the present study, self-administration tests were conducted daily and it might be expected that nicotinic receptors might have remained in a partially desensitized state due to the extended and regular daily exposure to nicotine. This receptor desensitization might result in decreased efficacy of mecamylamine in the self-administration tests. However, during the reinstatement tests that were conducted 2 weeks after completion of nicotine selfadministration phase, receptor function would have recovered from its desensitization state so that mecamylamine produced a stronger effect.

The finding that mecamylamine dose-dependently attenuated cue-induced reinstatement extends the evidence for a role of nicotinic neurotransmission in mediating the reinforcing actions of nicotine (Mathieu-Kia et al, 2002; Watkins et al, 2000a; Wonnacott et al, 2005 for reviews) to the incentive motivational effects of nicotine-associated cues. Moreover, two recent studies (Cohen et al, 2005; Paterson et al, 2005) have shown that $\mathrm{GABA}_{\mathrm{B}}$ agonist (CGP44532), cannabinoid (CB1) antagonist (rimonabant, SR141716), and dopamine D1 antagonist (SCH23390) reduced nicotine cue-induced recovery of nicotine-seeking responses. In addition, recent studies showing that systemic administration of nicotine increases glutamate release in ventral tegmental area (VTA) and nucleus accumbens (NAc) (Reid et al, 2000; Schilstrom et al, 2000) and that mecamylamine attenuates glutamate-mediated response (Clarke et al, 1994) suggest possible involvement of glutamatergic neurotransmission. Therefore, multiple neurotransmitter systems such as acetylcholine, dopamine, GABA, cannabinoid, and glutamate seem to be implicated in mediating this function. The present data do not provide information on the neuroanatomical substrates through which nicotinic blockade attenuated reinstatement of nicotine-seeking. However, there is evidence showing that nicotinic mechanisms in the hippocampus, VTA, and NAc might play a critical role in modulating the process of learning and memory in general (Kim and Levin, 1996; Schildein et al, 2002). Studies by using functional magnetic resonance imaging in humans (Brody et al, 2002, 2004; Due et $a l, 2002)$ and expression of immediately early gene product (Fos and Arc) in rats (Schiltz et al, 2005; Schroeder et al, 2001) have also shown similar brain regions that are activated by exposure to smoking- or nicotine-related cues. Underpinning neurobiological substrates for mediating conditioned reinstatement of nicotine-seeking warrants future studies.

In summary, this study demonstrates that re-exposure to nicotine-associated cue significantly reinstated nicotineseeking behavior after extinction in rats. More importantly, the results demonstrate that mecamylamine attenuated the cue-induced reinstatement of nicotine-seeking behavior in a dose-dependent manner but did not alter food-taking and -seeking behavior, indicating its specificity for reversal of nicotine-seeking. These data suggest that nicotinic neurotransmission may be a potential target for developing pharmacotherapeutic strategies to treat and prevent nicotine relapse.

\section{ACKNOWLEDGEMENTS}

This work was supported by the State of California TRDRP Grant 12RT-0188 and NIH Grants DA17288 (X Liu) and DA10464 (AR Caggiula) from National Institute on Drug Abuse.

\section{REFERENCES}

Adams ML, Cicero TJ (1998). Nitric oxide mediates mecamylamine- and naloxone-precipitated nicotine withdrawal. Eur $J$ Pharmacol 345: R1-R2.

Anggadiredja K, Sakimura K, Hiranita T, Yamamoto T (2004). Naltrexone attenuates cue- but not drug-induced methamphetamine seeking: a possible mechanism for the dissociation of primary and secondary reward. Brain Res 1021: 272-276.

Bechtholt AJ, Mark GP (2002). Enhancement of cocaine-seeking behavior by repeated nicotine exposure in rats. Psychopharmacology (Berlin) 162: 178-185.

Blokland A (1995). Acetylcholine: a neurotransmitter for learning and memory? Brain Res Brain Res Rev 21: 285-300.

Brody AL, Mandelkern MA, Lee G, Smith E, Sadeghi M, Saxena S et al (2004). Attenuation of cue-induced cigarette craving and anterior cingulate cortex activation in bupropion-treated smokers: a preliminary study. Psychiat Res 130: 269-281.

Brody AL, Mandelkern MA, London ED, Childress AR, Lee GS, Bota RG et al (2002). Brain metabolic changes during cigarette craving. Arch Gen Psychiat 59: 1162-1172.

Butschky MF, Bailey D, Henningfield JE, Pickworth WB (1995). Smoking without nicotine delivery decreases withdrawal in 12-h abstinent smokers. Pharmacol Biochem Behav 50: 91-96.

Caggiula AR, Donny EC, White AR, Chaudhri N, Booth S, Gharib MA et al (2001). Cue dependency of nicotine self-administration and smoking. Pharmacol Biochem Behav 70: 515-530.

Childress AR, Hole AV, Ehrman RN, Robbins SJ, McLellan AT, O'Brien CP (1993). Cue reactivity and cue reactivity interventions in drug dependence. NIDA Res Monogr 137: 73-95.

Clarke PB, Chaudieu I, el-Bizri H, Boksa P, Quik M, Esplin BA et al (1994). The pharmacology of the nicotinic antagonist, 
chlorisondamine, investigated in rat brain and autonomic ganglion. Br J Pharmacol 111: 397-405.

Clarke PB, Kumar R (1983). Nicotine does not improve discrimination of brain stimulation reward by rats. Psychopharmacology (Berlin) 79: 271-277.

Cohen C, Perrault G, Griebel G, Soubrie P (2005). Nicotineassociated cues maintain nicotine-seeking behavior in rats several weeks after nicotine withdrawal: reversal by the cannabinoid (CB1) receptor antagonist, rimonabant (SR14 1716). Neuropsychopharmacology 30: 145-155.

Corrigall WA, Coen KM (1989). Nicotine maintains robust selfadministration in rats on a limited-access schedule. Psychopharmacology (Berlin) 99: 473-478.

Curzon P, Brioni JD, Decker MW (1996). Effect of intraventricular injections of dihydro-beta-erythroidine (DH beta E) on spatial memory in the rat. Brain Res 714: 185-191.

Dallery J, Houtsmuller EJ, Pickworth WB, Stitzer ML (2003). Effects of cigarette nicotine content and smoking pace on subsequent craving and smoking. Psychopharmacology (Berlin) 165: $172-180$.

Donny EC, Caggiula AR, Mielke MM, Booth S, Gharib MA, Hoffman A et al (1999). Nicotine self-administration in rats on a progressive ratio schedule of reinforcement. Psychopharmacology (Berlin) 147: 135-142.

Drobes DJ, Tiffany ST (1997). Induction of smoking urge through imaginal and in vivo procedures: physiological and self-report manifestations. J Abnorm Psychol 106: 15-25.

Droungas A, Ehrman RN, Childress AR, O'Brien CP (1995). Effect of smoking cues and cigarette availability on craving and smoking behavior. Addict Behav 20: 657-673.

Due DL, Huettel SA, Hall WG, Rubin DC (2002). Activation in mesolimbic and visuospatial neural circuits elicited by smoking cues: evidence from functional magnetic resonance imaging. $\mathrm{Am}$ J Psychiat 159: 954-960.

Eissenberg T, Griffiths RR, Stitzer ML (1996). Mecamylamine does not precipitate withdrawal in cigarette smokers. Psychopharmacology (Berlin) 127: 328-336.

Epstein DH, Preston KL (2003). The reinstatement model and relapse prevention: a clinical perspective. Psychopharmacology (Berlin) 168: 31-41.

Girod R, Role LW (2001). Long-lasting enhancement of glutamatergic synaptic transmission by acetylcholine contrasts with response adaptation after exposure to low-level nicotine. $J$ Neurosci 21: 5182-5190.

Glick SD, Maisonneuve IM, Kitchen BA (2002). Modulation of nicotine self-administration in rats by combination therapy with agents blocking alpha 3 beta 4 nicotinic receptors. Eur $J$ Pharmacol 448: 185-191.

Goldberg SR, Spealman RD, Goldberg DM (1981). Persistent behavior at high rates maintained by intravenous self-administration of nicotine. Science 214: 573-575.

Grimm JW, See RE (2000). Dissociation of primary and secondary reward-relevant limbic nuclei in an animal model of relapse. Neuropsychopharmacology 22: 473-479.

Gross J, Lee J, Stitzer ML (1997). Nicotine-containing vs denicotinized cigarettes: effects on craving and withdrawal. Pharmacol Biochem Behav 57: 159-165.

Haikala H, Ahtee L (1988). Antagonism of the nicotine-induced changes of the striatal dopamine metabolism in mice by mecamylamine and pempidine. Naunyn Schmiedebergs Arch Pharmacol 338: 169-173.

Hamada M, Higashi H, Nairn AC, Greengard P, Nishi A (2004). Differential regulation of dopamine D1 and D2 signaling by nicotine in neostriatal neurons. J Neurochem 90: 1094-1103.

Hildebrand BE, Panagis G, Svensson TH, Nomikos GG (1999). Behavioral and biochemical manifestations of mecamylamineprecipitated nicotine withdrawal in the rat: role of nicotinic receptors in the ventral tegmental area. Neuropsychopharmacology 21: $560-574$.

Horger BA, Giles MK, Schenk S (1992). Preexposure to amphetamine and nicotine predisposes rats to self-administer a low dose of cocaine. Psychopharmacology (Berlin) 107: 271-276.

Kalivas PW, McFarland K (2003). Brain circuitry and the reinstatement of cocaine-seeking behavior. Psychopharmacology (Berlin) 168: 44-56.

Kantak KM, Black Y, Valencia E, Green-Jordan K, Eichenbaum HB (2002). Dissociable effects of lidocaine inactivation of the rostral and caudal basolateral amygdala on the maintenance and reinstatement of cocaine-seeking behavior in rats. J Neurosci 22: $1126-1136$.

Kim JS, Levin ED (1996). Nicotinic, muscarinic and dopaminergic actions in the ventral hippocampus and the nucleus accumbens: effects on spatial working memory in rats. Brain Res 725: 231-240.

Kouri EM, Stull M, Lukas SE (2001). Nicotine alters some of cocaine's subjective effects in the absence of physiological or pharmacokinetic changes. Pharmacol Biochem Behav 69: 209-217.

Kuo DY, Lin TB, Huang CC, Duh SL, Liao JM, Cheng JT (1999). Nicotine-induced hyperlocomotion is not modified by the estrous cycle, ovariectomy and estradiol replacement at physiological level. Chin J Physiol 42: 83-88.

Lazev AB, Herzog TA, Brandon TH (1999). Classical conditions of environmental cues to cigarette smoking. Exp Clin Psychopharmacol 7: 56-63.

LeSage MG, Burroughs D, Dufek M, Keyler DE, Pentel PR (2004). Reinstatement of nicotine self-administration in rats by presentation of nicotine-paired stimuli, but not nicotine priming. Pharmacol Biochem Behav 79: 507-513.

Liu X, Caggiula AR, Yee SK, Nobuta H, Poland RE, Pechnick RN (2006). Reinstatement of nicotine-seeking behavior by drugassociated stimuli after extinction in rats. Psychopharmacology (Berlin) 184: 417-425.

Liu X, Koren AO, Yee SK, Pechnick RN, Poland RE, London ED (2003). Self-administration of 5-iodo-A-85380, a beta2-selective nicotinic receptor ligand, by operantly trained rats. NeuroReport 14: 1503-1505.

Liu X, Weiss F (2004). Nitric oxide synthesis inhibition attenuates conditioned reinstatement of ethanol-seeking, but not the primary reinforcing effects of ethanol. Alcohol Clin Exp Res 28: 1194-1199.

Loiacono R, Stephenson J, Stevenson J, Mitchelson F (1993). Multiple binding sites for nicotine receptor antagonists in inhibiting $\left[{ }^{3} \mathrm{H}\right](-)$-nicotine binding in rat cortex. Neuropharmacology 32: 847-853.

Lukas RJ, Ke L, Bencherif M, Eisenhour CM (1996). Regulation by nicotine of its own receptors. Drug Dev Res 38: 136-148.

Lundahl LH, Henningfield JE, Lukas SE (2000). Mecamylamine blockade of both positive and negative effects of IV nicotine in human volunteers. Pharmacol Biochem Behav 66: 637-643.

Mansbach RS, Chambers LK, Rovetti CC (2000). Effects of the competitive nicotinic antagonist erysodine on behavior occasioned or maintained by nicotine: comparison with mecamylamine. Psychopharmacology (Berlin) 148: 234-242.

Mansvelder HD, Keath JR, McGehee DS (2002). Synaptic mechanisms underlie nicotine-induced excitability of brain reward areas. Neuron 33: 905-919.

Mathieu-Kia AM, Kellogg SH, Butelman ER, Kreek MJ (2002). Nicotine addiction: insights from recent animal studies. Psychopharmacology (Berlin) 162: 102-118.

McCallum SE, Caggiula AR, Booth S, Breese CR, Lee MJ, Donny EC et al (2000). Mecamylamine prevents tolerance but enhances whole brain $\left[{ }^{3} \mathrm{H}\right]$ epibatidine binding in response to repeated nicotine administration in rats. Psychopharmacology (Berlin) 150: $1-8$ 
McDermut W, Haaga DA (1998). Effect of stage of change on cue reactivity in continuing smokers. Exp Clin Psychopharmacol 6: 316-324.

Mucha RF, Pauli P, Angrilli A (1998). Conditioned responses elicited by experimentally produced cues for smoking. Can J Physiol Pharmacol 76: 259-268.

Nemeth-Coslett R, Henningfield JE, O'Keeffe MK, Griffiths RR (1986). Effects of mecamylamine on human cigarette smoking and subjective ratings. Psychopharmacology (Berlin) 88: $420-425$.

Niaura R, Abrams D, Demuth B, Pinto R, Monti P (1989). Responses to smoking-related stimuli and early relapse to smoking. Addict Behav 14: 419-428.

Nisell M, Nomikos GG, Svensson TH (1994). Systemic nicotineinduced dopamine release in the rat nucleus accumbens is regulated by nicotinic receptors in the ventral tegmental area. Synapse 16: 36-44.

O’Brien CP, Childress AR, Ehrman R, Robbins SJ (1998). Conditioning factors in drug abuse: can they explain compulsion? J Psychopharmacol 12: 15-22.

Olausson P, Jentsch JD, Taylor JR (2003). Repeated nicotine exposure enhances reward-related learning in the rat. Neuropsychopharmacology 28: 1264-1271.

Paterson NE, Froestl W, Markou A (2005). Repeated administration of the GABAB receptor agonist CGP44532 decreased nicotine self-administration, and acute administration decreased cue-induced reinstatement of nicotine-seeking in rats. Neuropsychopharmacology 30: 119-128.

Payne TJ, Schare ML, Levis DJ, Colletti G (1991). Exposure to smoking-relevant cues: effects on desire to smoke and topographical components of smoking behavior. Addict Behav 16: 467-479.

Pich EM, Pagliusi SR, Tessari M, Talabot-Ayer D, Hooft van Huijsduijnen R, Chiamulera C (1997). Common neural substrates for the addictive properties of nicotine and cocaine. Science 275: 83-86.

Reid MS, Fox L, Ho LB, Berger SP (2000). Nicotine stimulation of extracellular glutamate levels in the nucleus accumbens: neuropharmacological characterization. Synapse 35: 129-136.

Reid MS, Mickalian JD, Delucchi KL, Berger SP (1999). A nicotine antagonist, mecamylamine, reduces cue-induced cocaine craving in cocaine-dependent subjects. Neuropsychopharmacology 20: 297-307.

Reid MS, Mickalian JD, Delucchi KL, Hall SM, Berger SP (1998). An acute dose of nicotine enhances cue-induced cocaine craving. Drug Alcohol Depend 49: 95-104.

Rezvani AH, Levin ED (2001). Cognitive effects of nicotine. Biol Psychiat 49: 258-267.

Rose JE, Behm FM (2004). Extinguishing the rewarding value of smoke cues: pharmacological and behavioral treatments. Nicotine Tob Res 6: 523-532.

Rose JE, Behm FM, Westman EC (1998). Nicotine-mecamylamine treatment for smoking cessation: the role of pre-cessation therapy. Exp Clin Psychopharmacol 6: 331-343.

Rose JE, Behm FM, Westman EC, Johnson M (2000). Dissociating nicotine and nonnicotine components of cigarette smoking. Pharmacol Biochem Behav 67: 71-81.

Rose JE, Behm FM, Westman EC, Levin ED, Stein RM, Ripka GV (1994). Mecamylamine combined with nicotine skin patch facilitates smoking cessation beyond nicotine patch treatment alone. Clin Pharmacol Ther 56: 86-99.

Rose JE, Levin ED, Behm FM, Westman EC, Stein RM, Lane JD et al (1995). Combined administration of agonist-antagonist as a method of regulating receptor activation. Ann NY Acad Sci 757: 218-221.

Rose JE, Sampson A, Levin ED, Henningfield JE (1989). Mecamylamine increases nicotine preference and attenuates nicotine discrimination. Pharmacol Biochem Behav 32: 933-938.
Schildein S, Huston JP, Schwarting RK (2002). Open field habituation learning is improved by nicotine and attenuated by mecamylamine administered posttrial into the nucleus accumbens. Neurobiol Learn Mem 77: 277-290.

Schilstrom B, Fagerquist MV, Zhang X, Hertel P, Panagis G, Nomikos GG et al (2000). Putative role of presynaptic alpha7* nicotinic receptors in nicotine stimulated increases of extracellular levels of glutamate and aspartate in the ventral tegmental area. Synapse 38: 375-383.

Schiltz CA, Kelley AE, Landry CF (2005). Contextual cues associated with nicotine administration increase arc mRNA expression in corticolimbic areas of the rat brain. Eur J Neurosci 21: 1703-1711.

Schroeder BE, Binzak JM, Kelley AE (2001). A common profile of prefrontal cortical activation following exposure to nicotine- or chocolate-associated contextual cues. Neuroscience 105: 535-545.

Shaham Y, Adamson LK, Grocki S, Corrigall WA (1997). Reinstatement and spontaneous recovery of nicotine seeking in rats. Psychopharmacology (Berlin) 130: 396-403.

Shaham Y, Shalev U, Lu L, De Wit H, Stewart J (2003). The reinstatement model of drug relapse: history, methodology and major findings. Psychopharmacology (Berlin) 168: 3-20.

Shahan TA, Bickel WK, Madden GJ, Badger GJ (1999). Comparing the reinforcing efficacy of nicotine containing and de-nicotinized cigarettes: a behavioral economic analysis. Psychopharmacology (Berlin) 147: 210-216.

Shiffman S, Mason KM, Henningfield JE (1998). Tobacco dependence treatments: review and prospectus. Annu Rev Public Health 19: 335-358.

Shoaib M, Schindler CW, Goldberg SR (1997). Nicotine selfadministration in rats: strain and nicotine pre-exposure effects on acquisition. Psychopharmacology (Berlin) 129: 35-42.

Surawy C, Stepney R, Cox T (1985). Does watching others smoke increase smoking? $B r \mathrm{~J}$ Addict 80: 207-210.

Takayama H, Majewska MD, London ED (1989). Interactions of noncompetitive inhibitors with nicotinic receptors in the rat brain. J Pharmacol Exp Ther 251: 1083-1089.

Tiffany ST, Hakenewerth DM (1991). The production of smoking urges through an imagery manipulation: psychophysiological and verbal manifestations. Addict Behav 16: 389-400.

Varanda WA, Aracava Y, Sherby SM, VanMeter WG, Eldefrawi ME, Albuquerque EX (1985). The acetylcholine receptor of the neuromuscular junction recognizes mecamylamine as a noncompetitive antagonist. Mol Pharmacol 28: 128-137.

Varvel SA, James JR, Bowen S, Rosecrans JA, Karan LD (1999). Discriminative stimulus (DS) properties of nicotine in the C57BL/6 mouse. Pharmacol Biochem Behav 63: 27-32.

Watkins SS, Epping-Jordan MP, Koob GF, Markou A (1999). Blockade of nicotine self-administration with nicotinic antagonists in rats. Pharmacol Biochem Behav 62: 743-751.

Watkins SS, Koob GF, Markou A (2000a). Neural mechanisms underlying nicotine addiction: acute positive reinforcement and withdrawal. Nicotine Tob Res 2: 19-37.

Watkins SS, Stinus L, Koob GF, Markou A (2000b). Reward and somatic changes during precipitated nicotine withdrawal in rats: centrally and peripherally mediated effects. J Pharmacol Exp Ther 292: 1053-1064.

Wonnacott S, Sidhpura N, Balfour DJ (2005). Nicotine: from molecular mechanisms to behaviour. Curr Opin Pharmacol 5: 53-59.

Yin R, French ED (2000). A comparison of the effects of nicotine on dopamine and non-dopamine neurons in the rat ventral tegmental area: an in vitro electrophysiological study. Brain Res Bull 51: 507-514.

Zarrindast MR, Barghi-Lashkari S, Shafizadeh M (2001). The possible cross-tolerance between morphine- and nicotineinduced hypothermia in mice. Pharmacol Biochem Behav 68 283-289. 